\title{
The Prioritization of Special Educator Well-Being: An Empirical Perspective of Contemporary Importance
}

\author{
Katherine Carpenter-Ware, Ed.D., Meredith Welch, Ed.D., and Sandra Battige, Ph.D.
}

Liberty University

\section{ABSTRACT}

Purpose: This study aimed to describe the subjective well-being of experienced special education teachers in one mid-Atlantic state in the United States. The significance of this study was amplified by the onset of COVID-19. These circumstances were reflected within the data and provide implications for school administrators. Methods: Qualitative data collection methods, including semi-structured interviews, focus groups, and audio journals, were used to generate data from twelve experienced special education teachers. Research Design: A transcendental phenomenological methodology, framed within Martin Seligman's well-being theory, structured this study. Findings: The themes that arose from the data indicated that experienced special education teachers sourced positive emotions, engagement, relationships, meaning, and accomplishment from role-related experiences. However, barriers to these elements of well-being and negative emotions were also described. Some of this data aligned with previous literature and some data was shaped by the unique experiences of early pandemic virtual instruction. Conclusions: Culminating from the data are practical implications for K-12 school leaders to provide intentional support for the retention and well-being of special educators. Of these implications, acknowledging the hefty paperwork demands within the role, prioritizing teacher planning time, and expressing appreciation could benefit the well-being of those who teach within the special education community.

Keywords: COVID-19, special education teachers, K-12 school leadership, teacher well-being, well-being theory
*Correspondence to Author:

Katherine Carpenter-Ware, Ed.D. Liberty University

How to cite this article:

Katherine Carpenter-Ware, Meredith Welch, Sandra Battige. The Prioritization of Special Educator Well-Being: An Empirical Perspective of Contemporary Importance. American Journal of Educational Research and Reviews, 2022,7:88.

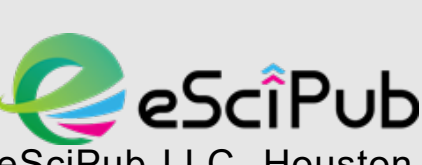

eSciPub LLC, Houston, TX USA. Website: https://escipub.com/ 


\section{Introduction}

Teaching is identifiably a stressful profession (Cancio et al., 2018; Cook et al., 2017; Elreda et al., 2018; Garwood et al., 2018; Jennings et al., 2017; Macintyre et al., 2019; Mankin et al., 2018; Roberts et al., 2019; Skaalvik \& Skaalvik, 2018; Taylor, Roberts, Zarrett, 2021; Wong et al., 2017). Stress among teachers presents as an unpleasant emotion that results from various occupational demands (Skaalvik \& Skaalvik, 2018; Robinson et al., 2019). A Gallep survey ranked teaching as more stressful than careers in nursing or medicine (Jennings et al., 2017). A 2013 Metlife survey indicated that $59 \%$ of American teachers reported feeling stressed, increasing from the $35 \%$ who reported feeling stressed in 1985 (Jennings et al., 2017). Among K-12 educators, special educators experience more stress than general education teachers (Bettini et al., 2017, Cancio et al., 2018; Conley \& You, 2017; Garwood et al., 2018; Robinson et al., 2019). Stressful teachers are more likely to leave the profession (Billingsley \& Bettini, 2019; Brownell et al., 2018; Brownell et al., 2019; Conley \& You, 2017; Robinson et al., 2019; Rumschlag, 2017; Wong et al., 2017). Overall, there is a lack of information about the coping mechanisms of teachers and how to lead teachers with a prioritization on well-being at the helm (Cancio et al., 2018; Garwood et al., 2018). Teachers' stress has several consequences, as it influences the quality of instruction, diminishes student outcomes, and decreases student engagement (Elreda et al., 2018; Wong et al., 2017). Teachers who experience stress are less likely to have a sense of accomplishment and may have difficulty finding meaning within their work (Cancio et al., 2018; Robinson et al., 2019). Stress also impacts personal and professional relationships (Cancio et al., 2018; Hagaman \& Casey, 2018). With accomplishment and relationships being elements of well-being, it is of critical significance that teacher stress levels impede these elements (Seligman, 2011). Thus, the well-being of teachers is of utmost criticality as we continue functioning within a continuous period of societal disruption spurred by COVID19 (Wyse et al., 2020).

Before COVID-19, teacher stress contributed to burnout and attrition-fueled shortages (CarverThomas \& Darling-Hammond, 2018; Taylor, Roberts, \& Zarrett, 2021). Specifically, teacher shortages were a prevalent challenge for public schools across the United States (Bettini et al., 2017; Cancio et al., 2018; Carver-Thomas \& Darling-Hammond, 2019; Lesh et al., 2017). This challenge was evident before the unanticipated and extensive societal impacts of COVID-19 (Marazziti \& Stahl, 2020). In response to a pre-existing understaffed teacher workforce, a transcendental phenomenological study, framed within Seligman's (2011) well-being theory, was designed to capture the well-being status of experienced special educators in the mid-Atlantic region of the United States. Although the researcher designed this study before impacts of COVID-19 becoming evident in the United States, data collection occurred following COVID-19 school closures in the spring of 2020. The timeliness of data collection provided a qualitative array of insight related to the workplace actuality of experienced special educators during their pre-COVID-19 workdays and their experiences teaching virtually during the school closures prompted by COVID-19. The collected data represents experienced special educators who have remained in the profession for longer than four years, signifying that the perspectives acquired were of experienced and retained teachers. Ultimately, the data revealed the following five themes. First, positive and negative emotions, accomplishment, and meaning were similarly derived from directly teaching students. Second, engagement was identified within creating and delivering instructional activities. Third, relationships were central to the workplace well-being of SETs. Fourth, there were commonly experienced barriers to well-being that the participants navigated within their special education teaching roles. Lastly, relationships and meaning were supported by participants' involvement in the 
development of novice and pre-service teachers. Also, the timely relevance of additional future research, centralized on teacher wellbeing during and following times of societal stress and uncertainty, resulted from the data (Marazziti \& Stahl, 2020).

The well-being theory (WBT) was introduced by Martin Seligman in 2011 and sprouted from within positive psychology (Kun et al., 2017). According to Seligman's (2011) theory, wellbeing is inclusive of five elements. These elements include positive emotions, engagement, relationships, meaning, and accomplishment, each underpinned by individual strengths (Seligman, 2011). Well-being is not an entirely subjective experience but can be objectively measured (Butler \& Kern, 2016; Seligman, 2011). As Seligman (2011) described, wellbeing does not solely exist in a person's mind but is an observable construct.

Positive emotions, such as joy, happiness, and calmness, are the good feelings that motivate human behavior (Kun et al., 2017; McQuaid \& Kern, 2017; Neumeier et al., 2017). Positive and negative emotions can be experienced alongside each other (Butler \& Kern, 2016). Previously, a link was identified between low positive affect and heightened C-Reactive Protein levels, a biomarker for inflammation in the human body (Ironson et al., 2018). Therefore, the literature indicates that emotional experiences can surface objectively within the physical health of human beings, as measured by various biomarkers (Holdsworth, 2019).

The element of engagement entails intense concentration (Kun et al., 2017). Previously, engagement has was described as flow (Butler \& Kern, 2016). The engagement has been shown to impact job satisfaction, job performance, profitability, customer satisfaction, and employee retention (Anthony-McCann et al., 2017). When the element of engagement was researched among teachers, it was negatively associated with emotional exhaustion, a component of burnout (Skaalvik \& Skaalvik, 2018). Since time and feeling cease while experiencing engagement, this element is identifiable retrospectively (Seligman, 2011).

Seligman (2011) indicated that some of life's best moments occur amongst other people. Relationships are necessary for life and influence human beings' emotional and physical health (Butler \& Kern, 2016; Pietromonaco \& Collins, 2017). Physiologically, the presence of a supportive relationship during times of stress can buffer cardiovascular reactivity (Pietromonaco \& Collins, 2017). In the workplace, relationships predicted commitment and job satisfaction (Kern, 2014).

Meaning embodies the valuable contributions of an individual and represents the driving force behind a person's work and indicates that individual persons are working toward a purpose (Butler \& Kern, 2016). Meaning is an essential element when humans encounter stressful life circumstances (Czekierda et al., 2017). The element of meaning was linked to an improved state of physical health, reduced mortality risk, and enhanced life satisfaction (Butler \& Kern, 2016). In the workplace, individuals who reported greater meaningfulness at work reported lower levels of depressive symptoms. These individuals were less likely to exhibit behaviors that were risky to their physical health (Czekierda et al., 2017).

Accomplishment is a necessary component for an individual's well-being and is pursued for its own sake, even when it does not render any emotion or meaningfulness (Kun et al., 2017; Seligman, 2011). In western society, achievement is recognized and acknowledged, and the celebration of related life events enhances individual well-being (Butler \& Kern, 2016; Pietromonaco \& Collins, 2018). Accomplishment is one of the indicators for burnout on the Maslach Burnout Inventory (Chetlan et al., 2019). Accomplishment can be evaluated by subjective and objective measures, as success is uniquely perceived (Butler \& Kern, 2016).

Mental health challenges were becoming increasingly prevalent in the workplace before the onset of COVID-19 (Neumeier et al., 2017). 
As society continues to grapple with impacts related to the pandemic, well-being is increasingly relevant when studying humans in the workplace (Neumeier et al., 2017). The wellbeing of employees is impactful upon the success of an organization (Kun et al., 2017; Slemp et al., 2015; Williams et al., 2015). Employment-related wellness is of enhanced criticality, as society persists among the unusuality that COVID-19 spurred. Prolonged exposure to stress, such as the stress experienced with the shift in day-to-day societal functioning, could present a risk factor for anxiety and depression (Kujawa et al., 2020). Burnout can also result from prolonged stress (Skaalvik \& Skaalvik, 2018; Robinson et al., 2018). When considering the workplace, wellbeing is of current priority to society.

While studying workplace well-being is necessary, investigating the well-being of teachers also holds timely significance. Previously, it was determined that teacher wellbeing predicted students' well-being (Global Council for Happiness and Well-being, 2019; Harding et al., 2019; Morrish et al., 2018). With American teachers managing stressful roles while simultaneously taking on the stressors brought forth by the pandemic, the well-being of the teacher workforce is of heightened importance (Garwood et al., 2018). Stress impacts teacher effectiveness and the elements of well-being (Roberts et al., 2019). The wellbeing theory offers an appropriate lens for observing teachers' well-being before, during, and following times of societal disruption.

The attrition of special education teachers (SETs) among teachers is a documented challenge for public education in most of the United States (Bettini et al., 2017; Cancio et al., 2018; Carver-Thomas \& Darling-Hammond, 2019; Lesh et al., 2017). This challenge was palpable ahead of the pandemic in the United States. However, this already costly issue of SET attrition is being amplified by the additional SET vacancies for school divisions stemming from the pandemic (Carver-Thomas \& Darling-
Hammond, 2019; University Council for Education Administration, 2018). Before the onset of COVID-19, the shortage of SETs in the United States was critical in some states (Lesh et al., 2017). As COVID-19 has spanned more than a year, SET shortages, student outcomes, and the need for a qualified teacher workforce generate increasing significance, fueling studies on teacher well-being. The relevance of these inquiries is of contemporary relevance as society begins to look towards patterns of former normalcy.

Based on pre-pandemic evidence, the teacher shortage crisis in the United States was most influenced by teacher attrition (Carver-Thomas \& Darling-Hammond, 2019; Geiger \& Pivovarova, 2018; Kelchtermans, 2017; Lesh et al., 2017). In the United States, teacher attrition was estimated to cost 4.9 billion dollars annually (University Council for Education Administration, 2018). Additionally, at the state level, it is estimated that attrition among SETs costs states several hundred thousand dollars annually (Carver-Thomas \& Darling-Hammond, 2019). While teacher attrition is certainly of cost to society, more importantly, it is impactful upon student outcomes. Considering that the impacts of the pandemic on learner outcomes are undefined, teacher attrition remains a topic of critical significance as we sift through the challenges brought on by the pandemic. However, to discover the associations which reflect in present-day society, the previously confirmed attrition factors require consideration (Bettini et al., 2017; Billingsley \& Bettini, 2017; Cook et al., 2017; Global Council for Happiness and Well-being, 2019; Hagaman \& Casey, 2018; MacIntyre et al., 2019; Um et al., 2018; Wong et al., 2017).

\section{Background}

Before the pandemic onset, approximately onethird of special education teachers departed the field within their first three years of service (Cancio et al., 2018). When previously measured, the national rate of voluntary attrition among SETs was $46 \%$ (Billingsley \& Bettini, 
2017). However, SET turnover is more likely among Title I schools and schools serving 55\% or more students of color. These schools have a turnover rate of $80 \%$ (Billingsley \& Bettini, 2019; Carver-Thomas \& Darling-Hammond, 2019). These numbers convey the issue's prevalence but do not capture the characteristics or experiences of the departing SETs.

The characteristics of SETs departing the field, and the reasons influencing their decisions to leave the profession, were previously categorized by Billingsley (2004). The current literature on the topic builds from Billingsley's categorization of attrition (2004). Although dated, the most likely demographic to depart the special education field was age, with younger, less-experienced teachers, more likely to leave the profession (Billingsley, 2004; CarverThomas \& Darling-Hammond, 2019; Conley \& You, 2017). Similarly, an evident challenge is filling SET vacancies perpetuated by the turnover of young SETs with little experience, with similar young and inexperienced SETs (Billingsley \& Bettini, 2017; Mastropieri et al., 2017). Also of note is that some SETs take on teaching positions before completing their teacher preparation programs. These teachers take upon the role of SET with provisional licensure, seizing the professional teaching role before fulfilling all degree requirements. SETs entering the field through this route have demonstrated a greater likelihood of leaving the profession (Bettini et al., 2020; Mastropieri et al., 2017). This cyclical challenge of replacing younger, inexperienced SETs with young SETs with little experience leaves the field of special education in need of qualified teachers prepared to take upon the unique role requirements of a special educator.

Although academically prepared to take a special education teaching assignment, many pre-service SETs harbor a disillusioned perception of the reality of the role (Fowler et al., 2019; Hagaman \& Casey, 2018; Gavish, 2017). However, administrators' understanding of the role is also misaligned from reality, creating an ambiguous and complex role for SETs to partake (Bettini et al., 2020; Rock et al., 2016). The misunderstanding of the role, or a perceived lack of respect for the role, and the role ambiguity that persists creates role conflict and role overload for those teachers working in special education teaching roles (Young, 2018; Conley \& You, 2017). Ultimately, these factors, or role problems, are harmful to the well-being of special educators (Garwood et al., 2018).

Special educators bear a range of complex professional role-related responsibilities, including demanding and challenging teaching positions (Bettini et al., 2017). Workload manageability has previously supported SETs' likelihood to remain in the field (Bettini et al., 2017). Overwhelming workloads can impact teachers' energy levels, resulting in less engagement and a sense of burnout (Cancio, 2018). A component of the SET workload is paperwork. The paperwork demands required of special educators have been categorized as excessive and outweigh the paperwork required of general education teachers (Bettini et al., 2017; Mastropieri et al., 2017). The paperwork requirements of special educators are tasks associated with Individualized Education Plan (IEP) development and maintenance, student assessments and related data collection, behavior intervention plans, lesson plans, additional data collection related to student progress and behavior, student progress reports, and communication logs with parents (Bateman \& Cline, 2016; Mastropieri et al., 2017; Ruble et al., 2018).

IEPs require collaboration among a team of educators and service providers (Bateman, 2017). This collaborative group frequently includes SETs, general education teachers, representatives of the public education agency, a professional to interpret student evaluations and assessments, students, parents, or guardians of students (Bateman, 2017). While developing IEPs requires input from all team members, the responsibility to ensure these collaborative efforts develop into an executable 
education plan rests on the SET. Many general and special educators lack preparation for the extensive collaboration required to meet students' needs (Gomez-Najarro, 2019). Having adequate time to meet is the greatest obstacle to cooperation between teachers ( $\mathrm{Da}$ Fonte \& Barton-Arwood, 2017). The impact of the pandemic on teachers' ability to collaborate is an unresearched topic.

While collaboration is a necessary component of the SET teaching role, collegial relationships are an essential workplace factor for special educators (Collins et al., 2017; Ruppar et al., 2017). Collegial relationships are relationships with fellow teachers that provide informal mentoring in the workplace (Collins et al., 2017; Ruppar et al., 2017). SETs' need to form meaningful relationships extends beyond the collaboration required by SETs' teaching roles (Ruppar et al., 2017). SETs experience unique difficulty identifying informal mentors with whom they can form fruitful connections (Billingsley, Bettini, \& Jones, 2019). Relationships also embody a primary element of well-being (Seligman, 2011). Relationships' criticality is reflected in the previous literature related to SETs functioning within their extensively collaborative role.

School culture is related to workplace conditions for teachers. Workplace conditions have influenced teachers' choices to leave the profession (Geiger \& Pivovarova, 2018; Harris et al., 2019; Lesh et al., 2017). Relatively, it was discovered that teachers working at higherperforming schools have greater retention rates (Geiger \& Pivovarova, 2018). Effective school culture is synonymous with a collaborative environment exuding a sense of shared responsibility (Lee \& Louis, 2019). Positive school culture can reinforce a teacher's commitment to teaching and contribute to teachers' greater job satisfaction in their workplaces (Bettini et al., 2017). When considering the influence of school culture, among the challenges presented by COVID-19, qualitative inquiry provided an opportunity to understand what may have supported teacher commitment during periods of prolonged virtual instruction and separation from students during the pandemic.

Teachers have one of the most stressful occupations, and previous research on special educators' experiences are commonly associated with negative affect (Cancio et al., 2018; Cook et al., 2017; Elreda et al., 2018; Garwood et al., 2018; Ironson et al., 2018; Jennings et al., 2017; Macintyre et al., 2019; Mankin et al., 2018; Roberts et al., 2019; Skaalvik \& Skaalvik, 2018; Wong et al., 2017). However, Seligman's well-being theory directed this inquiry. Utilizing this theoretical lens, the goal of this study was to seek out the sustainability of SET well-being within the context of contemporary teacher workplaces. In doing so, data collection was targeted at capturing the reality of SETs' day-to-day teaching experiences. Therefore, a specific affect, such as stress, was not isolated for this inquiry to develop a whole and realistic description of experienced SET well-being. Ultimately, due to the timeliness of data collection, participants' workplace experiences were described in terms of pre-pandemic backgrounds and their experiences during virtual instruction during periods of prolonged virtual K-12 education during the pandemic.

\section{Participants}

Following IRB approval, twelve SETs provided consent to participate in the study. The sampling criteria included licensed SETs with a minimum of four years of experience teaching special education and those who were actively employed in special education teaching positions (Billingsley \& Bettini, 2019; Ruppar, Roberts, \& Olson, 2017). The range of special education teaching experience among participants was between five and thirty-seven years. However, the mean amount of teaching experience among the twelve participants was 20 years, representing a sample of teachers with extensive classroom experience. The participants were sourced from a suburban 
community within a particular state in the midAtlantic region of the United States. Participants were actively teaching students spanning grades $\mathrm{K}-12$ with a range of instructional needs and abilities. The participants taught in various instructional settings, including self-contained classrooms, inclusion environments, and resource classrooms. At the time of data collection, all participants were delivering instruction via virtual technologies.

\section{Procedures}

Transcendental phenomenology was used to design a study generating a description of the well-being of experienced special education teachers in one mid-Atlantic state within the United States. This design was chosen to develop a raw and description of the SETs' experiences. IRB approval was received less than one week after public schools in the sampling region were closed due to COVID-19 in March 2020. Data collection occurred between May 2020 and June 2020 through semi-structured interviews, audio diaries, and focus groups. Descriptive data was generated using the Workplace PERMA Profiler (Kern, 2014). Following data collection and transcription, data analysis followed Moustakas' (1994) modification of the Stevick-Colazzi Keen Method, which occurred over a series of phenomenological reductions. NVivo served as an assistive resource during data analysis.

\section{Results}

Through a series of phenomenological reductions, five themes emerged as components of experienced special educator well-being. The themes revealed were reflective of the five elements of well-being. Participants' responses collected during semi-structured interviews, focus group discussions, and audio diary entries were reflective of their retrospective teaching experiences before the onset of the pandemic and representative of their experiences teaching during periods of prolonged virtual instruction beginning in March 2020. The audio-diary responses captured the participants' emotions at the conclusions of their workdays during the prolonged period of virtual schooling in the spring of 2020.

Students were the most frequently mentioned contributor to multiple elements of the participants' well-being. This theme arose from within the data and reflected the participants' centralized care and concern for students. The data indicated that interactions with students contributed to the elements of positive emotions, meaning, and accomplishment-additionally, participants' commonly referenced concerns for equitable treatment of students. The lack of inperson interactions with students during the initial months of virtual instruction following the onset of COVID-19 was also identifiable. This data represented a source of negative emotions for the participants. Table 1 indicates the resulting themes of this study.

Table 1 Frequency of Data Informing Each Theme Across all Sources

\begin{tabular}{|c|c|c|c|}
\hline Theme & Interviews & Focus Group & Audio Diary \\
\hline $\begin{array}{l}\text { Students: Contribute to positive and negative emotions, meaning, and } \\
\text { accomplishment }\end{array}$ & 77 & 5 & 37 \\
\hline Relationships: Integral to SET workplace well-being & 53 & 9 & 19 \\
\hline Engagement: Sourced from creating and delivering instruction & 18 & 1 & 4 \\
\hline Common role-related barriers to well-being & 24 & 62 & 7 \\
\hline $\begin{array}{l}\text { Relationships and meaning: Sourced from participating in the } \\
\text { development of pre-service and novice teachers }\end{array}$ & 9 & 2 & 2 \\
\hline
\end{tabular}


Positive emotions resulted from directly working with and instructing students. Participants described hands-on learning experiences as the primary instructional method which rendered positive emotions. When specifying hands-on learning activities used in the classroom, participants described group work and literacy activities. Another participant reported positive emotions streaming from functional learning activities, where she felt learning was most meaningful for her students to function in their daily lives. Participants also reported positive emotions resulting from outcomes. The student achievements described varied but included witnessing students learn new content, achieve IEP goals, or make behavioral progress.

Similarly, participants indicated that meaning was sourced from their relationships with students and the opportunities to witness positive student outcomes. The participants described these outcomes differently based upon their unique instructional settings and the students they serve. Specifically, the results described included functional learning activities, academic achievements, social skills, or postsecondary career and education opportunities. Relationships with students were a contributor to teacher meaning. One participant described herself as an advocate and friend for students. Another teacher discussed the meaningfulness of observing students grow and achieve across a period, observing student development from middle school into their high school years.

Participants described students' outcomes and individual progress as sources for the accomplishment. One participant noted achievement when others, such as general education teachers or administrators, noticed her students' progress. Another participant described that accomplishment streamed from students expressing enjoyment in the learning process. Similarly, another participant described a sense of accomplishment generated by students completing and submitting work. The participant described this as celebratory for students who struggled to complete and submit their work in the past.

The participants described caring for students' equitable treatment amongst their non-disabled peers. These concerns for their students rendered negative emotions for participants. Some participants noted that these negative emotions came from worrying about students during school closures, such as during weekends or holidays. Similarly, one participant cited a worry related to students' access to resources at home, explaining that some of her students live transiently, reside in hotels, and have difficulty accessing virtual instruction.

Students remained centralized within participants' comments related to COVID-19. Participants expressed concerns related to future learning gaps and difficulties contacting students since the closing of schools. One participant reported an inability to contact any of her students via virtual face-to-face technologies upon the initial shutdown of schools in March 2020. This participant described feelings of sadness related to feeling a sense of failure about motivating her students. However, this participant expressed feelings of happiness when she encouraged a student using a GIF. One participant described virtual instruction tearfully and detailed missing her students and face-to-face instruction.

The participants described a common interest in creating and delivering instructional experiences for students. This component of the SET teaching role seemed to be most impeded by the paperwork demands encompassed by their teaching roles defined by the participants. When commenting on their experiences with virtual instruction following the onset of COVID-19, participants voiced that engagement diminished during the periods of prolonged virtual instruction characteristic of the initial months of COVID-19 in the United States. These comments supported the well-being element of engagement and were consistent among participants. 
When describing role-related activities which generate engagement, the most word most frequently used by participants was "make." Teachers described feeling a sense of engagement with creating instructional activities for students. These activities ranged from integrating technology into instruction, designing individualized behavioral support systems, or designing instructional materials for students. One teacher described feeling a sense of engagement with creating literacy units for her student. This participant described spending summer months reviewing and selecting literature for her students. She further explained making instructional activities to form a literacy unit for students. Another teacher described SmartBoard activities as engaging because she feels her students benefit from interactive lessons.

When participants discussed experiences related to teaching during COVID-19, teachers described a lack of engagement related to the inability to provide in-person opportunities. One teacher indicated limited student attendance and participation. While teachers reported limited sources for engagement during prolonged virtual instruction, several teachers reported actively preparing hands-on instructional materials for the following school year. Some participants reported hand-making student materials that they delivered to students' porches as they planned for at-home learning. However, one participant described how limiting distance learning felt.

Relationships emerged as integral to the participants' well-being, underscoring relationships as a primary pillar of well-being. Of the contributors to professional SET well-being, workplace relationships seemed to be the most consistently cited during COVID-19. Participants discussed positive workplace relationships in several categories, including relationships with paraprofessionals, co-teachers, administrators, and relationships with other SETs. The descriptions provided by participants were representative of the support that was available and exchanged with co-workers during prolonged virtual instruction.

The participants identified a variety of workplace relationships as integral to their workplace experiences. Participants assigned to selfcontained classrooms frequently commented on their teacher assistants or paraprofessionals. Participants assigned to inclusion settings often referred to their co-teachers and the mutual respect existent between them. The participants also discussed building collegial and essential relationships with other special educators within their department. One participant reported that these relationships had been the best throughout her career. Participants also commented on their relationships with administrators. The participants shared mostly positive experiences with their administrators, both past and present. One participant described the benefits and perceived support related to her administrator's special education background and a willingness to provide hands-on classroom support.

While the participants described various challenges in communicating with students during virtual instruction, the participants reported maintaining workplace relationships through different technological methods during times of school closures. One participant, a high school teacher, described working alongside a colleague to place yards signs outside of senior students' homes as they were preparing to graduate. Other participants described weekly Zoom happy hours and frequent group text messaging throughout workdays to sync with their colleagues. Participants mentioned regularly scheduled virtual meetings for all classroom staff and frequently scheduled virtual meetings with administrators.

The participants described role-related challenges that impeded their well-being. One participant identified that she had experienced burnout during earlier years in her career and expressed that she addressed the burnout by switching from working in the inclusion setting to working in a self-contained environment. When 
discussing barriers to well-being, the teachers described experiencing negative emotions, and most participants articulated their coping methods. Additionally, some participants cited specific reasons which would be causal for departing the special education profession.

Participants described role-related experiences which rendered negative emotions for them. Participants frequently mentioned excessive paperwork as a constant barrier to well-being. Additionally, teachers felt negative emotions arise from being uninformed or unprepared to manage student behaviors. Several participants described a lack of recognition from division administrators and described division administrators as out of touch with the daily reality in the classrooms. Also, students remained a common and consistent concern for the teachers. The participants described feeling negative emotions related to the fair treatment of students. Several participants described negative emotions resulting from standardized testing for students. Standardized testing was cited as a contributor to one participant's burnout and was also described as irrelevant and unnecessary to some students by another participant.

Most participants described methods for coping with their teaching roles. These methods included regular exercise, socializing with other special education teachers, and alcohol consumption. One participant could not identify a process that she used for coping with her teaching role. This participant indicated that this was a current struggle for her. When describing her experience with burnout, one participant explained moving from a co-teaching assignment to a self-contained classroom, where she was working with students with autism. She described this change in instructional settings as assistive to overcoming her burnout. She emphasized feeling a sense of newness every day and the positive emotions she draws from working with a new roster of students each year. The participants described having additional paperwork during virtual instruction during the initial months of COVID-19. One participant estimated that paperwork demands had tripled since the onset of the pandemic. One participant described a lack of meaning and accomplishment from a hefty workload and limited opportunities to teach students via virtual methods. Another participant reported decreased sleep and an inability to separate her work environment from her home environment while teaching virtually. Another participant reported feeling helpless and limitedness related to her ability to support students through virtual methods. These experiences led one participant to describe struggling with the emotions associated with teaching virtually during COVID19.

Each of the participants described participating in supporting novice teachers. Some participants described formal mentorship roles to assist novice SETs, while others commented on contributing as informal mentors to novice teachers in their school buildings. Some participants reported being assigned to co-teach with novice general educators to provide informal support in that setting. These relationships were described as generating meaning and relationships for the participants. One participant who was nearing retirement experienced SETs helped her when she was a novice teacher, and novice teachers now seek guidance and support from her. In actively participating in support of inexperienced teachers, the participants commented on needs within the profession. The support of novices during the initial months of COVID-19, either informally or formally, was infrequently mentioned throughout all modes of data collection.

The participants described relationships with novice teachers through their service as cooperating teachers for student teaching assignments, supporting general or special educators informally, or developing relationships through formal mentorships with novice special educators. One participant reflected on not having a mentor available to her when she 
began her special education career. This participant described the benefits of mentorship programs and how mentorship could have benefited her. One participant described deriving a sense of meaning from being assigned to co-teach with novice general educators. She expressed that she feels one of her primary, yet unofficial, roles as an experienced educator are to educate educators.

One participant described the necessity of mentorship programs to develop novice educators and explained that her school's mentorship program could use additional structure and organization. This participant reported feeling unsure what her role was compared to the part of administrators when it came to supporting a novice special educator. Another participant explained that she needed additional time to support and mentor a novice SET adequately. Another participant discussed continuing her relationship with a studentteacher as the novice educator began her career. However, the novice teacher reported being given additional roles and responsibilities at the onset of her teaching career, ultimately leading to her departing the field within the first year of teaching.

While teachers described methods for maintaining contact with various workplace relationships during COVID-19, the maintenance of relationships or interactions with novices or mentees was infrequently mentioned by participants. One participant did describe the fruitful and positive experience of her coteaching relationship while teaching virtually. This participant noted that her assigned coteacher, a novice, harbored impeccable skills related to delivering virtual instruction, so they could divide instructional responsibilities while optimizing the use of both of their skill sets. This scenario was the only interaction with novices mentioned during data collection, so the extent of support provided to newer teachers during COVID-19 is unknown from the data collected by this study and requires further retrospective inquiry.

\section{Discussion}

The findings of this study, using Seligman's (2011) WBT, exude implications for SETs and the school administrators that support them. WBT proposes five elements that support wellbeing: positive emotions, engagement, relationships, meaning, and accomplishment. The following information provides suggestions for school administrators to better support the well-being of SETs.

Rendering the most negative emotion and serving as a constant barrier to well-being for SETs are the copious amounts of paperwork that are required of the special educator role. The amount of time that SETs spend writing and maintaining IEPs, assessments, data collection, behavior intervention plans, lessons plans, progress reports, and communication logs is excessive (Bateman \& Cline, 2016; Bettini et al., 2017; Mastropieri et al., 2017; Ruble et al., 2018). Causing SETs even more frustration is the lack of recognition that is received by division administrators for their efforts. In fact, some administrators are referred to as out of touch with the daily reality of classrooms. It is imperative that school administrators find intentional ways to enhance the well-being of SETs in order both increase productivity and student achievement but also retention in the field (Vittek, 2015).

To better support the well-being of SETs through the element of positive emotion, it is important that administrators acknowledge the impact that additional paperwork has on SETs workload and overall positivity towards the role. While verbally acknowledging this impact is likely appreciated, finding ways to appreciate SETs time is invaluable. Administrators should evaluate the additional demands that are placed on their SETs in order to determine if there are roles and responsibilities that could be redistributed. A prime example of this redistribution could occur using supervisory duty roles. In addition, school administrators should consider creative ways of providing additional planning time to SETs. Utilizing funds to provide full day subs or 
coverage in order to free up this time is palpable recognition of the time that is spent completing tasks required of the special education role and demonstrates a willingness to promote the positive emotions of SETs in order to improve their overall well-being.

Engagement can impact job satisfaction, performance, profitability, customer satisfaction, and employee retention (Anthony-McCann et al., 2017). The findings of this study revealed that SETs feel engaged when creating instructional activities for students. Activities ranging from technology integration, designing individual behavioral support systems, or designing instructional materials for students takes time. As such, school administrators must be intentional to provide adequate planning time for SETs (Bettini, et al., 2015). Protecting SETs planning time by avoiding other meetings and conflicts should be a primary way that school administrators enhance the well-being of SETs. In doing so, SETs have dedicated time to engage in making activities for their students which in turn increases their performance and commitment to their role. School administrators should be mindful that pandemic planning and material preparation looks different. Because of this, it is possible that providing professional development or training opportunities for SETs could increase engagement and efficacy in providing students' technology-enhanced materials (Bettini et al., 2017).

Relationships increase individuals' well-being by increasing organizational commitment and job satisfaction (Bettini, et al., 2015; Kern, 2014). In order to manage their responsibilities, SETs rely on relationships with colleagues (Cancio et al., 2018; Conley \& You, 2017). SET relationships can exist among paraprofessionals, coteachers, relationships with other SETs, intradepartmental SETs and school administrators. While administrators can certainly provide collaborative opportunities for SETs to engage with other school personnel, administrators must acknowledge the role that their relationship has on SETs well-being in the workplace (Bettini, et al., 2015; Conley \& You, 2017). Participants from this study shared mostly positive experiences with their administrators citing evidence of support through administrators' understanding of special education as well as providing handson classroom support.

These findings reveal several ways that school administrators can be intentional in building relationships with their SETs. First, administrators, regardless of their background in special education, must be willing to educate themselves on special education processes, law, and best practices (Bettini et al., 2017). SETs are depending on administrators, who quite often serve as the Local Education Agency (LEA) or designee in meetings, to be a knowledgeable advocate for the special education team. Administrators should also develop relationships with SETs through discussions about caseloads, current successes, and challenges, as well as student progress. Third, school administrators must be willing to provide hands-on classroom support when needed. These three tasks, supported by the findings of this study, could have a direct impact on relationships among SETs and therefore increase their well-being.

Meaning, also described as having a direction, working towards a purpose, and feeling valuable (Butler \& Kern, 2016) are essential to SETs wellbeing in the workplace. The findings of this study identified two ways that SETs increase their meaning. SETs indicate that their meaning in the workplace is sourced through their relationships with students and observing positive student outcomes. In addition, SETs identified a source of meaning from serving as cooperating teachers, support for general or special education teachers, and through developing mentorships with novice special educators (Vittek, 2015). As evidenced from one of the participants in this study, SETs believe that one of their primary roles as an educator is to educate educators. To not only support novice special educators in the field but to also enhance 
meaning for current SETs, school administrators should seek opportunities to develop structured mentorship programs. Moreover, it is imperative that school administrators consider mentoring pairings of experienced SETs with novice SETs.

Well-being is also reliant on accomplishment (Kun, Balogh, \& Krasz, 2017). Administrators' understanding of the SET role is often misaligned from reality causing ambiguity for SETs (Bettini et al., 2020; Rock et al., 2016). The misunderstanding of the role, or a perceived lack of respect for the role, and the role ambiguity that persists creates role conflict and role overload for those teachers working in special education teaching roles (Young, 2018; Conley \& You, 2017). Ultimately, these factors, or role problems, are harmful to the well-being of special educators (Garwood et al., 2018). In order to increase feelings of accomplishment, school administrators should seek intentional ways to acknowledge and celebrate SETs (Bettini, et al., 2015). Examples of acknowledgement could include handwritten notes, duty or lunch coverage, lunch ordered in, and jeans days. In addition to school administrators, participants in this study stated that they feel accomplished when general education teachers see success with behavioral and academic strategies that are generalized across settings.

Seligman's (2011) well-being theory identifies positive emotions, engagement, relationships, meaning and accomplishment as influential elements of individuals' well-being. School administrators can and should find intentional ways to support WBT's elements to increase SETs commitment and retention to teaching special education. Through purposeful and creative planning opportunities, relationships, mentorships, and acknowledgement, school administrators can support SETs well-being in the workplace.

\section{Limitations}

The sample size of this study was a limiting factor. A larger sample size could yield additional insight or further underscore the themes revealed within this study's data. Additionally, sampling began in March 2020, shortly after the onset of school closures related to the pandemic. This characteristic may have further impacted the sample size.

This study was designed to investigate SET wellbeing before knowledge of COVID-19's societal impacts. However, data collection followed the school closures related to the pandemic. While the data collected was influenced by experiences related to prolonged virtual instruction following the onset of COVID-19, the study was not designed to determine or measure the effects of the pandemic on teachers. Therefore, the intentional investigation of teacher well-being during and following the pandemic is necessary. An intentionally designed study could incorporate data collection tools that may illuminate pandemic-related emotions and experiences among participants.

This study was conducted at the end of the 2019-2020 school year. Collecting data towards the end of the school year could have influenced teacher attitudes in an immeasurable way. Replicating this study at the onset of the school year could yield different results. Additionally, this study only included female participants and lacked racial and ethnic diversity. Therefore, the experiences of male participants, and participants from various racial and ethnic backgrounds, are absent from the data. These characteristics limit the scope of understanding that could be drawn from the results. Lastly, the literature clearly outlines the challenges inherent to the practice of SETs across the nation; however, this study only included participants from a particular mid-Atlantic state.

\section{Conclusion}

While this study on experienced SET well-being bore an initial aim to address the criticality of special education teacher shortages throughout most of the United States, the pandemic coincided with data collection, and further revealed that teacher well-being is of contemporary priority. The impact of the https://escipub.com/american-journal-of-educational-research-and-reviews/ 
pandemic on the teacher workforce is yet to fully captured through research data and presents a gap in the literature requiring theoretical-based inquiry. However, the qualitative data revealed within this study provided implications for school administrators to consider as they continue to provide leadership to educators within America's pandemic-responsive society. Prioritizing teacher well-being through the action-based implications described, could render support to educators, as the research community embraces opportunities to fully capture the extent of impact the pandemic has imposed on the wellbeing of K-12 educators in the United States.

\section{References}

[1]. Bettini, E., Benedict, A., Thomas, R., Kimerling, J., Choi, N., \& McLeskey, M. (2017).Cultivating a community of effective special education teachers: Local special education Administrators' roles. Remedial and Special Education, 38(2), 111-126.

[2]. Cancio, E.J., Larsen, R., Mathur, S.R., Estes, M.B., Johns, B., \& Chang, M. (2018). Special education teacher stress: Coping strategies. Education and Treatment of Children, 41(4), 457.

[3]. Carver-Thomas, D., \& Darling-Hammond, L. (2019). The trouble with teacher turnover: How teacher attrition affects students and schools. Education Policy Analysis Archives, 27(36), 1-32.

[4]. Jennings, P.A., Frank, J.L., Doyle, S., Oh, Y., Rasheed, D., Deweese, A., Cham, H., Brown, J., Davis, R., Demauro, A.A., \& Greenberg, M.T. (2017). Impacts of care for teachers program on teachers' social and emotional competence and classroom interactions. Journal of Educational Psychology, 109(7), 1010-1028.

[5]. Taylor, S.G., Roberts, A.M., \& Zarrett, N. (2021). A brief mindfulness-based intervention (bMBI) to reduce teacher stress and burnout. Teaching and Teacher Education, $100 . \quad$ doi: https://doi.org/10.1016/j.tate.2021.103284

[6]. Anthony-McCann, P.E., Ellinger, A.D., Astakhova, M., \& Halbesleben, J.R.B. (2017). Exploring different operationalizations of employee engagement and their relationships with workplace stress and burnout. Human Resource Development Quarterly, 28(2), 163-195.

[7]. Bateman, B. (2017). Individual Education Programs for Children with Disabilities. In J.M. Kauffman, D.D. Hallahan, \& P.C. Pullen (Eds.), Handbook of Special Education (pp. 87-104). New York, NY: Routledge.
[8]. Bateman, D.F., \& Cline, J.L. (2016). A teacher's guide to special education. ASCD: Alexandria, $\mathrm{Va}$.

[9]. Bettini, E., Allison, G.F., Williams, T.O. \& Billingsley, B. (2020). Predicting special educatorand general educators' intent to continue teaching using conservation of resources theory. Exceptional Children. https://doi.org/10.1177/0014402919870464

[10]. Bettini, E., Benedict, A., Thomas, R., Kimerling, J., Choi, N., \& McLeskey, M. (2017). Cultivating a community of effective special education teachers: Local special education Administrators' roles. Remedial and Special Education, 38(2), 111-126.

https://doi.org/10.1177/07419325166647

90

[11]. Bettini, E. A., Cheyney, K., Wang, J., \& Leko, C. (2015). Job design: An Administrator's guide to supporting and retaining special educators. Intervention in School and Clinic, 50(4), 221-225. https://doi.org/10.1177/1053451214532346

[12]. Billingsley, B. (2004). Special education teacher retention and attrition: A critical analysis of the research literature. The Journal of Special Education, 38(1), 39-55.

[13]. Billingsley, B., \& Bettini, E. (2017). Improving special education teacher quality and effectiveness. In J.M. Kauffman, D.D. Hallahan, \& P.C. Pullen (Eds.), Handbook of Special Education (pp. 501-520). New York, NY: Routledge.

[14]. Billingsley, B., \& Bettini, E. (2019). Special education teacher attrition: $A$ review of the literature. Review of Educational Research. https://doi.org/10.3102/0034654319862495

[15]. Billingsley, B., Bettini, E., \& Jones, N.D. (2019). Supporting special education teacher induction through high-leverage practices. Remedial and Special Education, 40(6), 365-379. https://doi.org/10.1177/0741932518816826

[16]. Brownell, M.T., Bishop, A.M., \& Sindelar, P.T. (2018). Republication of "NCLB" and the demand for highly qualified teachers: Challenges and solutions for rural schools. Rural Special Education Quarterly, 37(1), 4-11.

[17]. Brownell, M.T., Bettini, E., Pua, D., Peyton, D., \& Benedict, A.E. (2019). Special education teacher effectiveness in an era of reduced federal mandates and increasing teacher shortages. In J.B. Crockett, B. Billingsley, \& M.L. Boscardin (Eds.), Handbook of leadership and administration for special education. Retrieved from https://books.google.com 
[18]. Butler, J., \& Kern, M.L. (2016). The perma profiler: A brief multidimensional measure of well- being. International Journal of Well-being, 6, 1-48.

[19]. Cancio, E.J., Larsen, R., Mathur, S.R., Estes, M.B., Johns, B., \& Chang, M. (2018). Special education teacher stress: Coping strategies. Education and Treatment of Children, 41(4), 457.

[20]. Carver-Thomas, D., \& Darling-Hammond, L. (2019). The trouble with teacher turnover: How teacher attrition affects students and schools. Education Policy Analysis Archives, 27(36), 1-32.

[21]. Chetlan, A.L., Chan, T.L., Ballard, D.H., Frigini, A., Hildebrand, A., Kim, S., Brian, J.M., Krupinski, E.A., \& Ganeshan, D. (2019). Addressing burnout in radiologists. Academic Radiology, 26(4), 526533.

[22]. Conley, S., \& You, S. (2017). Key influences on special education teachers' intentions to leave: The effects of administrative support and teacher team efficacy in a mediational model. Educational Management Administration \& Leadership, 45(3), 521-540.

[23]. Cook, C.R., Miller, F.G., Fiat, A., Renshaw, T., Frye, M., Joseph, G., \& Decano, P. (2017). Promoting secondary teachers' well-being and intentions to implement evidence-based practices: Randomized evaluation of the achiever resilience curriculum. Psychology in the Schools, 54(1), 13-28.

[24]. Czekierda, K., Banik, A., Park, C.L., \& Luszczynska, A. (2017). Meaning in life and physicalhealth: Systematic review and metaanalysis. Health Psychology Review, 11(4), 387418.

[25]. Da Fonte, M.A., \& Barton-Arwood, S.M. (2017). Collaboration of general and special education teachers: Perspectives and strategies. Intervention in School and Clinic, 53(2), 99-106.

[26]. Elreda, L.M., Jennings, P.A., DeMauro, A.A., Mischenko, P.P., Brown, J.L. (2018). Protective Effects of interpersonal mindfulness for teachers' emotional supportiveness in the classroom. Mindfulness, $\quad 10, \quad 537-546$. https://doi.org/10.1007/s12671-018-0996-y

[27]. Fowler, S.A., Coleman, M.R.B., \& Bogdan, W.K. (2019). The state of the special education Profession survey report. Teaching Exceptional Children, 52(1), 8-29.

[28]. Garwood, J.D., Werts, M.G., Varghese, C., \& Gosey, L. (2018). Mixed-methods analysis of rural special educators' role stressors, behavior management, and burnout. Rural Special Education Quarterly, 37(1), 30-43.

[29]. Gavish, B. (2017). Special education trainee perceptions of their professional world: Motives, roles, and expectations from teacher training. Teachers and Teaching, 23(2), 153-170.

[30]. Geiger, T., \& Pivovarova, M. (2018). The effects of working conditions on teacher retention. Teachers and Teaching: Theory and Practice, 24(6), 604-625.

[31]. Global Council for Happiness and Well-being. (2019). Global happiness and well-being policy report 2019. New York, NY: Sustainable Development Solutions Network.

[32]. Gomez-Najarro, J. (2019). An empty seat at the table: Examining general and special education teacher collaboration in response to intervention. Teacher Education and SpecialEducation. https://doi.org/10.1177/0888406419850894

[33]. Hagaman, J.L., \& Casey, K.J. (2018). Teacher attrition in special education. Teacher Education and Special Education, 41(4), 277-291.

[34]. Harding, S., Morris, R., Gunnell, D., Ford, T., Holingworth, W., Tilling, K., Evans, R., Bell, S.,Grey, J., Brockman, R., Campbell, R., Araya, R., Murphy, S., \& Kidger, J. (2019). Is teachers' mental health and well-being associated with students' mental health andwell-being? Journal of Affective Disorders, 253, 460-466.

[35]. Harris, S.P., Davies, R.S., Christensen, S.S., Hanks, J., \& Bowles, B. (2019). Teacher attrition:Differences in stakeholder perceptions of teacher work conditions. Education Sciences, 9(4), 300. https://doi.org/10.3390/educsci9040300

[36]. Holdsworth, M. (2019). Health, wellness, and wellbeing. Revue Interventions Economiques, (62). https://doi.org/10.4000/interventionseconomique s.6322

[37]. Ironson, G., Banerjee, N., Fitch, C., \& Krause, N. (2018). Positive emotional well-being, health behaviors, and inflammation measured by creactive protein. Social Science \& Medicine, 197, 235-243.

[38]. Jennings, P.A., Frank, J.L., Doyle, S., Oh, Y., Rasheed, D., Deweese, A., Cham, H., Brown, J., Davis, R., Demauro, A.A., \& Greenberg, M.T. (2017). Impacts of care for teachersprogram on teachers' social and emotional competence and classroom interactions. Journal of Educational Psychology, 109(7), 1010-1028.

[39]. Kelchtermans, G. (2017). 'Should i stay or should i go?': Unpacking teacher attrition/retention asan educational issue. Teachers and Teaching, 23(8), 961-977.

[40]. Kern, M.L. (2014). The workplace perma-profiler [PDF file]. Retrieved fromhttp://www.peggykern.org/uploads/5/6/6/7/5 6678211/workplace_perma_profiler_102014.pdf 
[41]. Kujawa, A., Green, H., Compas, B.E., Dickey, L., Pegg, S. (2020). Exposure to COVID-19 pandemic stress: Associations with depression and anxiety in emerging adults in the United States. Depress Anxiety, 37, 1280-1288. DOI: 10.1002/da.23109

[42]. Kun, A., Balogh, P., \& Krasz, K.G. (2017). Development of the work-related well-being questionnaire based on seligman's perma model. Periodica Polytechica Social and Management Sciences, 25(1), 56-63.

[43]. Lee, M., \& Louis, K.S. (2019). Mapping a strong school culture and linking it to sustainable school improvement. Teaching and Teacher Education, 81 , 84-

96.https://doi.org/10.1016/j.tate.2019.02.001

[44]. Lesh, J.L., Shatz, K., Harris-Looby, J., Roberts, C. (2017). Why stay? A phenomenological look at special education teacher retention. International Journal of Education and Human Developments, 3(2), 12-24.

[45]. Maclntyre, P.D., Ross, J., Talbot, K., Mercer, S., Gregersen, T., \& Banga, C.A. (2019).Stressors, personality, and well-being among language teachers. System, 82, 26-38.

[46]. Mankin, A., von der Embse, N., Renshaw, T.L., Ryan, S. (2018). Assessing teacher wellness: Confirmatory factor analysis and measurement invariance of the teacher subjective well-being questionnaire. Journal of Psychoeducational Assessment, 36(3), 219-232.

[47]. Marazziti, D., \& Stahl, S.M. (2020). The relevance of the COVID-19 to psychiatry. World Psychiatry, 19(2), 261. DOI: 10.1002/wps.20764

[48]. Mastropieri, M.A., Scruggs, T.E., \& Hauth, C. (2017). Special education teacher preparation.In J.M. Kauffman, D.D. Hallahan, \& P.C. Pullen (Eds.), Handbook of Special Education(pp. 4051). New York, NY: Routledge.

[49]. McQuaid, M., \& Kern, P. (2017). Your well-being blueprint: Feeling good at work and doing well at work. Victoria, Australia: Michelle McQuaid Party Ltd.

[50]. Morrish, L., Rickard, N., Chin, T.C., VellaBrodrick, D.A. (2018). Emotional regulation in adolescent well-being and positive education. Journal of Happiness Studies, 19(5), 1543-1564.

[51]. Moustakas, C. (1994). Phenomenological Research Methods. Thousand Oaks, CA: Sage Publications.

[52]. Neumeier, L.N., Brook, L., Ditchburn, G., \& Phillipe, S. (2017). Delivering your daily dose ofwell-being to the workplace: A randomized controlled trial of an online well-being programme for employees. European Journal of Work and Organizational Psychology, 26(4), 555-573.
[53]. Pietromonaco, P.R., \& Collins, N.L. (2017). Interpersonal mechanisms linking close Relationships to health. American Psychologist, 72(6), 531-542.

[54]. Roberts, A.M., Gallagher, K.C., Daro, A.M., Iruka, I.E., Sarver, S.L. (2019). Workforce well-being: Personal and workforce contributions to early educators' depression across settings. Journal of Applied Developmental Psychology, 61, 4-12. https://doi.org/10.1016/j.appdev.2017.09.007

[55]. Robinson, O.P., Bridges, S.A., Rollins, L.H., \& Schumacker, R.E. (2019). A study of the relation between special education burnout and job satisfaction. Journal of Research in Special Educational Needs, 2(2), 1-9.

[56]. Rock, M.L., Spooner, F., Nagro, S., Vasquez, E., Dunn, C., Leko, M., Luckner, J., Bausch, M., Donehower, C., \& Jones, J.L. (2016). 21st century change drivers: Considering for constructing transformative models of special education teacher development. Teacher Education and Special Education, 39(2), 98-120.

[57]. Ruble, L.A., McGrew, J.H., Wong, W.H., \& Missall, K.A. (2018). Special education teachers' perceptions and intentions toward data collection. Journal of Early Intervention, 40(1),177-191.

[58]. Ruppar, A.L., Roberts, C.A., \& Olson, A.J. (2017). Perceptions about expert teaching for students with disabilities among teachers identified as experts. Research and Practice for Persons with Severe Disabilities, 42(2), 121-135.

[59]. Rumschlang, K. (2017). Teacher burnout: A quantitative analysis of emotional exhaustion,personal accomplishment, and depersonalization. International Management Review, 13(1), 22-36.

[60]. Seligman, M.E.P. (2011). Flourish: A visionary new understanding of happiness and well-being. New York, NY: Free Press.

[61]. Skaalvik, E.M., \& Skaalvik, S. (2018). Job demands and job resources as predictors of teacher motivation and well-being. Social Psychology of Education, 21, 12511275.https://doi.org/10.1007/s11218-018-9464-8

[62]. Slemp, G.R., Kern, M.L., \& Vella-Brodrick, D.A. (2015). Workplace well-being: The role of job crafting and autonomy support. Psychology of Well-being, 5(7), 1-17.

[63]. Taylor, S., Landry, C.A., Paluszek, M.M., Fergus, T.A., McKay, D., \& Asmundson, G.J.G.(2020). Covid stress syndrome: Concept, structure, and correlates. Depress Anxiety, 37, 706714.

[64]. University Council for Educational Administration. (2018). Policy Brief 2018-1: Addressing the Importance and Scale of the U.S. Teacher 
Shortage. Charlottesville, VA: Castro, A., Quinn, D.J., Fuller, E, \& Barnes, M.

[65]. Um, B., Joo, H., \& Her, D. (2018). The relationship between elementary school teachers' work motivation and well-being: The mediating effects of principal leadership and work stress. International Journal of Social Science Studies, 6(12), p. 67-78.

[66]. Vittek, J. E. (2015). Promoting special educator teacher retention: A critical review of the literature. SAGE Open, 5(2), 215824401558999.https://doi.org/10.1177/21582 44015589994

[67]. Williams, P., Kern, M.L., \& Waters, L. (2015). A longitudinal examination of the association Between psychological capital, perception of organizational virtues and work happiness in school staff. Psychology of Well-being, 5(5), 1-18.

[68]. Wong, V.W., Ruble, L.A., Yu, Y., \& McGrew, J.H. (2017). Too stressed to teach? Teachingquality, student engagement, and iep outcomes. Exceptional Children, 83(4), 412-427.

[69]. Wyse, A.E., Stickney, E.M., Butz, D., Beckler, A., \& Close, C.N. (2020). The potential impact of covid-19 on student learning and how schools can respond. Educational Measurement: Issues and Practice, $0(0), 1-5$.

[70]. Young, K. (2018). CO-CREATE: Teachers' voices to inform special education teachereducation. Issues in Educational Research, 28(1), 220-236. 